\title{
La chola boliviana en la primera mitad del siglo XX
}

De femme fatale a madre de la nación

\section{Ximena Soruco Sologuren}

\section{(2) OpenEdition}

Journals

Edición electrónica

URL: https://journals.openedition.org/agedor/1693

DOI: 10.4000/agedor.1693

ISSN: 2104-3353

Editor

Laboratoire LISAA

Referencia electrónica

Ximena Soruco Sologuren, «La chola boliviana en la primera mitad del siglo XX», L'Âge d'or [En línea],

10 | 2017, Publicado el 16 janvier 2018, consultado el 28 juin 2022. URL: http://

journals.openedition.org/agedor/1693; DOI: https://doi.org/10.4000/agedor.1693

Este documento fue generado automáticamente el 29 septiembre 2020.

L'Âge d'or. Images dans le monde ibérique et ibéricoaméricain 


\section{La chola boliviana en la primera mitad del siglo XX}

De femme fatale a madre de la nación

Ximena Soruco Sologuren

\section{Las Claudinas entran en escena ${ }^{1}$}

1 La Chaskañawi (1947) del escritor, crítico y profesor boliviano Carlos Medinaceli (Sucre 1902 - La Paz 1947) es la novela que inaugura la transformación de la representación sobre la chola ${ }^{2}$ en la literatura boliviana de la primera mitad del siglo XX, de una femme fatale mestiza a la madre que encarna la energía vital de la naturaleza y de la nación.

2 Esta es la historia de Adolfo Reyes, estudiante de derecho de Sucre que vuelve a su pueblo natal, San Javier de Chirca, Potosí tras la muerte de su padre. Este retorno al hogar paterno definirá su destino al enamorarse de la chola Claudina García, con quien acaba conviviendo y teniendo hijos, contra los prejuicios sociales de su estirpe y de su pueblo. La Chaskañawi inaugura en la literatura boliviana la historia de amor entre un señorito y una chola y con ello seguramente otorga legitimidad a este tipo de uniones en la sociedad. La propia vida del autor de la Claudina se confunde con su ficción, cuando conocemos que camina en público del brazo de una chola en Sucre, despreciando una premiación del Club de la Unión ${ }^{3}$ o tiene parejas cholas.

¿Bajo qué circunstancias se produce el cambio en el imaginario criollo sobre la chola de devora hombres a madre de la nación? Más allá de considerar que La Chaskañawi se escribe en un lapso de casi treinta años ${ }^{4}$, su propuesta tiene importantes antecedentes literarios: la novela En las tierras del Potosí (1911) de Jaime Mendoza y el cuento La Miskki-Simi (1921) de Adolfo Costa du Rels donde la protagonista chola lleva el mismo nombre que en la obra de Medinaceli: Claudina ${ }^{5}$ y la novela que cierra esta representación, La cruel Martina (1954) de Augusto Guzmán.

Claudina, personaje literario de estas tres obras, tiene su origen en el sur boliviano, entre Sucre y Potosí. La variante paceña de la chola trae características particulares que 
permiten observar una diferencia regional importante: se niega a la chola para idealizar a la "birlocha", la mestiza hija de chola pero ya vestida y educada a la manera occidental, que aparece en la novela La niña de sus ojos (1948) de Antonio Díaz Villamil (La Paz 1897-1948) y cuyo dilema identitario (la negación de la madre de pollera) enfrentan las obras de teatro popular del dramaturgo Raúl Salmón (La Paz 1926-1990).

Imagen 1

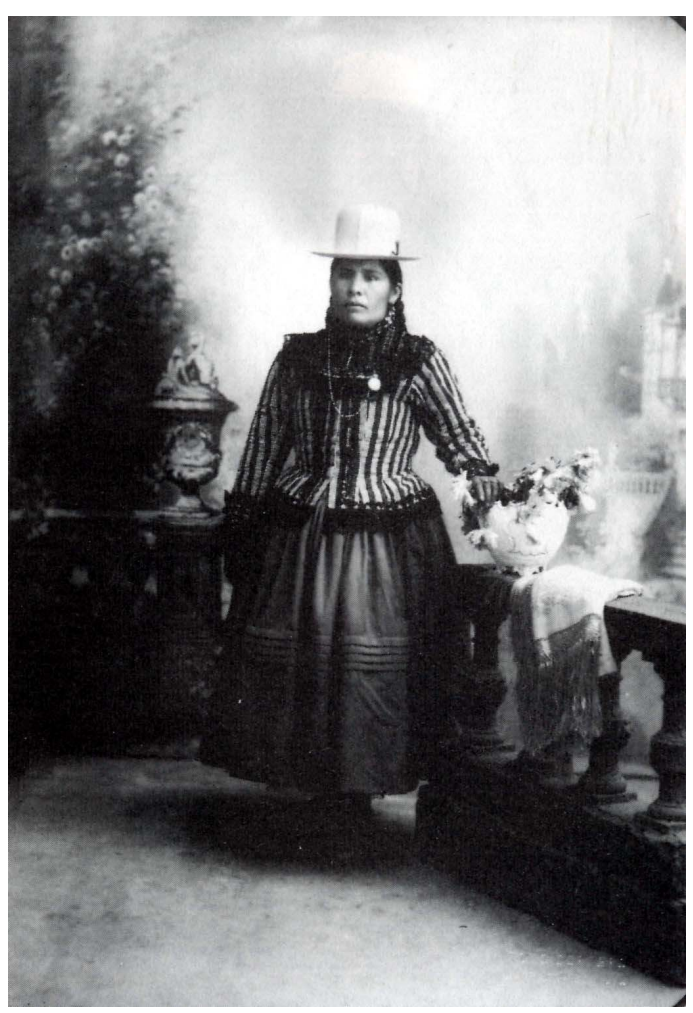

Chola paceña, 1910", Antonio Paredes Candia, La chola boliviana. La Paz, Isla, 1992.

Hay múltiples circunstancias sociales para explicar esta variante. Una estructural, puede ser la diferencia entre los procesos empíricos de mestizaje en el sur y el norte bolivianos. Mientras que la economía rural en el sur permitió la aparición de los pequeños propietarios campesinos y una inserción más temprana al mercado y a la política (Rodríguez) y su consiguiente mestización, en La Paz y Oruro se mantuvo la comunidad indígena, la mayoría de las veces sujeta a la hacienda. Los nuevos hacendados desde las leyes de exvinculación de 1874 reforzaron la exclusión del indígena aymara y con ella estimularon una resistencia más radical. En 1898 los rebeldes Aymaras que buscan la devolución de sus tierras comunitarias pactan con el Partido Liberal y contribuyen a la victoria de La Paz contra Sucre en la Guerra Federal (diciembre 1898-abril 1899). No solo se traslada la sede de gobierno a su sitio actual, sino que el ejército liberal es traicionado por los Aymaras sublevados bajo el mando de Zárate Willka quienes radicalizan sus demandas: una república india. Los siguientes años de hegemonía paceña también son los de una retórica de guerra de razas y de la diferenciación de los Quechuas (del sur) asimilados a la nación, frente a los Aymaras refractarios a la civilización. Lo que sorprende es que Cochabamba, lugar de intensa parcelación de la tierra en manos de campesinos, de los altos niveles educativos y participación política chola y presencia 
simbólica de la chichería y de la chola cochabambina ${ }^{6}$, no tenga una Claudina en su novelística durante la primera mitad del siglo XX.

En las tierras del Potosí (1911) de Jaime Mendoza (Sucre 1874-1939) es la primera novela que he encontrado donde la mirada criolla sugiere un potencial romance interétnico que también es interclasista. El protagonista criollo, Martín Martínez, se enamora fugazmente de una chola, es decir, amenaza la prohibición del romance exogámico, acostumbrado en la sociedad colonial y en la republicana del siglo XIX. Sin embargo, el desliz de Martínez no llega a ser más que una atracción pasajera que nunca se realiza porque la chola Claudina se escapa con un "mozuelo feo" y de menor condición social que él, un obrero7. Así, el romance que amenaza el statu quo acaba confirmándolo, Martín afirma la primera impresión que tuvo de las cholas en Llallagua, el centro minero al que fue de Sucre a buscar fortuna:

Las cholas le causaban repugnancia, y, ciertamente, lo que veía en ellas no era para agradar a un joven de sus gustos. Aquellas mujeres, que ordinariamente estaban sucias y desarrapadas, y que sólo en ciertos días se presentaban lavadas a medias y vistiendo trajes chillones y ridículos, no podían encantar ni mucho menos los ojos de Martín, que se acordaba de la graciosa y elegante indumentaria mujeril que antes viera en Sucre ${ }^{8}$.[...] Avergonzábale la idea de que se había dejado impresionar por una criatura semejante, por una chicuela de la más ínfima condición social, que siempre fue para él esquiva y huraña, que ni siquiera era inteligente, sino decididamente torpe, y que, por último, demostró ser de una condición tan liviana como estúpida. ${ }^{9}$

El amor a la chola así como su viaje al centro minero quedan atrás en la vida de Martín Martínez, quien retorna a Sucre para retomar su vida intelectual. Sin embargo, no deja de llamar la atención que aquí también la vida del novelista se mezcla con su ficción. Jaime Mendoza graduado de médico en 1901 trabaja en Llallagua y Uncía. En el primer centro minero conoce a su pareja Matilde Loza Oporto, una mujer de pollera y su único hijo, el historiador Gunnar Mendoza, nace en Uncía en 1914. Los prejuicios de Sucre en la época seguramente tuvieron que ver con que Jaime Mendoza no se casara con ella hasta poco antes de su muerte, ocurrida en $1930^{10}$.

La siguiente Claudina aparece diez años después en el cuento "La Miskki-Simi” (1921) del escritor boliviano francés Adolfo Costa du Rels (Sucre 1891, La Paz 1980).

Esta trama, al igual que la anterior, se desarrolla en un centro minero: Uyuni, pueblo surgido con la estación de tren y el comercio del estaño, "el gran igualador, [donde] desaparecían los desniveles sociales"11 y al que los criollos acudían en busca de fortuna, una veta de estaño en una concesión minera, un trabajo de oficina en una empresa minera, la experiencia para establecer una tienda de compra de mineral o venta de insumos, etc. En esta historia el protagonista, Jacobo Ávila, rompe los prejuicios sociales de su familia y casta y acaba viviendo con Claudina, la chola con "aureola de mujer fatal" 12

10 Como sucede con las novelas del 900, esta obra describe la chichería ${ }^{13}$ como un escenario proletario de comportamientos grotescos, "entre palmoteos y copas de aguardiente en una promiscuidad casi animal con mujeres ebrias y obreros soeces" ${ }^{14}$. De igual manera, Jaime Mendoza enfatiza la saturación que le causa el cuadro de un carnaval en Uyuni:

A cada momento se le llegaban hombres y mujeres, le abrazaban, le besaban y le ensuciaban. Derramaban sobre su ropa la chicha y el licor que le obligaban a beber [ ....]. Aquello era un cuadro repugnante. Un amasijo de carne humana, de chicha, de harapos, de polvos y de lodo ${ }^{15}$. 
11 Este cuadro grotesco, sin embargo, cumple la función de contrastar y resaltar la sensualidad de la chola, que sobresale, se individualiza del ambiente. El recurso que utiliza Costa du Rels es la voz narrativa de un testigo, el amigo del protagonista, que describe con objetividad la degradación moral y física de Jacobo Ávila en manos de Claudina y concluye con una moraleja de casta: quien se deja devorar por la sensualidad de una "boca maldita" acaba destruido, envilecido por el encholamiento o el descenso social.

No es casual que las protagonistas de estos tres textos tengan por nombre Claudina. Jaime Mendoza que escribe su novela en 1911, empieza a construir la imagen de una chola atractiva para el imaginario criollo. Aunque el argumento del amor entre Claudina y Martín no es el tema central de En las tierras del Potosí, este conflicto es el eje del cuento de Costa du Rels. De tal manera, La Miski Simi (1921), que en quechua significa "la de la boca dulce" tiene el poder de casi esclavizar a Jacobo. En este cuento, además, la caracterización de este personaje es más profunda porque se la describe como una mujer sensual pero caprichosa, con capacidad de manipular la voluntad del señorito: Claudina "pertenecía a la raza de las cortesanas, y, tal vez sin quererlo, jugaba con los hombres, como aquellos jugaban otrora con las perlas de sus collares" 16 .

Es interesante que esta cita resalte sutilmente la transformación de esta chola, Claudina juega con los hombres (criollos, de clase media) como ellos antes jugaron con ella. Me da la impresión que la referencia al pasado describe la posición que tiene la chola en las novelas de Armando Chirveches (La Paz 1881 - Paris 1926) o Enrique Finot (Santa Cruz 1881-1952) y su condición de objetos de las primeras experiencias sexuales de los señoritos en el contexto de servidumbre doméstica o en las chicherías durante la primera mitad del siglo XX. En esta narrativa, en cambio, la chola asume mayor poder de acción al invertir la situación, ahora es ella la que domina el juego sexual. Y el elemento que simboliza su poder en el cuento de Costa du Rels es su boca:

La boca. Sensual, carnosa, de un rojo violento, sabía manejar con pasmoso acierto la sonrisa dulce a la mueca desdeñosa. ¡Oh esa boca roja, roja sin más colorete que el que podía imponerle el beso! [....] Flor de lujuria que atraía a los colibríes para que agotaran su alma al borde de la maléfica corola [....] ¡Cuántos habían cedido ya a ese voluptuoso llamado de la Miskki-Simi! ${ }^{17}$

Boca que al mismo tiempo es dulce y maldita, que prodiga atención hasta atrapar a la víctima, pero que luego succiona su voluntad y vitalidad. La boca revela la tensión sensualidad-destrucción en esta chola. Su boca ofrece romance y sensualidad, pero también devora al hombre criollo que cae en su juego. Y la promesa de esa boca acaba destruyendo a Jacobo.

15 Tal es el poder de esta chola que esta vez, a diferencia de la novela de Jaime Mendoza, acaba en la convivencia, es decir, Costa du Rels empuja el romance con Claudina hasta sus últimas consecuencias, su "encholamiento":

[Jacobo] dejó de hablar de Cochabamba, dejó de hablar de la novia. En los labios de la Miskki-Simi había bebido el olvido. Algún tiempo después, supimos que vivía bajo el mismo techo en la calle del Peligro... Y así empezó el concubinato, el encholamiento. ${ }^{18}$

16 Aquí ya aparece un tema que será recurrente en la transición de la narrativa sobre la chola, de promiscua a madre: la chola doblega al amante criollo no sólo porque ha aprendido a jugar con él, sino por la debilidad de carácter del criollo. Ya no es la bancarrota económica y la consecuente alianza matrimonial con cholos ricos lo que 
preocupa a estos autores, aquí el deseo se ha metido en la piel, en la voluntad del sujeto criollo.

El criollo, entonces, acaba poco a poco cautivado, seducido y finalmente devorado por la "boca maldita" de las Claudinas porque no tiene la suficiente voluntad para resistirse a la "tentación" del encholamiento. Tanto Jacobo Ávila como Martín Martínez, el protagonista de En las tierras del Potosí, son letrados y por su ambición ambos van a los centros mineros buscando fortuna, para retornar a su hogar, los dos tienen una familia bien constituida y planes de matrimonio con una novia de su misma condición social (Jacobo en Cochabamba y Martín en Sucre); sin embargo, ambos adolecen de lo que los escritores de la época denominan "carácter" o "voluntad":

¿Sería que también su gusto se iba pervirtiendo? Martín, al pensar en esto [su atracción por una chola], no dejaba de sentirse avergonzado. Él nunca habría querido dar tal muestra de flaqueza. Pero la verdad era que ya miraba con ojos interesados a la jovencita Claudina ${ }^{19}$. [....] Percibí un dejo de fatalismo, que iría acentuándose más con el correr del tiempo. Lo noté vacilante, llevando al arrastre una voluntad poco tenaz. ${ }^{20}$

18 La "muestra de flaqueza" de Martín y "voluntad poco tenaz" de Jacobo pueden interpretarse como la falta la resistencia a "contaminarse" con su medio ambiente, es decir, con el ambiente obrero y cholo que habitan. Estos señoritos, descritos como moral y culturalmente superiores, acaban vencidos por su medio, es decir, el yo criollo se cosifica en el ambiente cholo y a partir de ahí el medio adquiere más agencia que el propio sujeto, como señala Costa du Rels: "más entre el alcohol y la chola, las voluntades zozobran y los caracteres envilecen".

Adolfo Reyes, el protagonista de La Chaskañawi de Carlos Medinaceli, sufre la misma tensión, su rendición al poder cautivador de una Claudina; sin embargo, en este caso el abandono de la vida occidental (ciudad, educación, trabajo burocrático y un matrimonio con una mujer criolla) es bastante reflexionado y acaba siendo una decisión, un acto consciente de selección entre la civilización y la naturaleza, entre una cultura abatida visión influida por La decadencia de Occidente de Spengler-, y la vitalidad de la tierra, representada por Claudina.

20 La diferencia entre las obras de Jaime Mendoza y Adolfo Costa du Rels y la de Carlos Medinaceli está en el abandono y la decisión; mientras las dos primeras narran el fatalismo de la agonía criolla en un ambiente cholo, la última asume la vitalidad chola como la única posibilidad de sobrevivencia para la desaparición de lo criollo: su mezcla.

21 En La Miski Simi y En las tierras del Potosí el abandono cultural de los criollos conlleva su degradación física y moral, y hasta su destrucción. En la primera, Jacobo Ávila se transforma completamente por su concubinato con Claudina:

La lenta soldadura de las costumbres hizo que Jacobo se identificara con ella. Por un extraño mimetismo, fruto de una pasión carnal exacerbada por libaciones nochariegas, identificó su personalidad con la de su compañera. En el primer beso, la Miskki-Simi le había transmitido su veneno, imponiéndole su ley. Arte femenino de la boca que se ofrece y de la boca que rehúye, juego sutil, exasperante, artimañas de la sonrisa o del mohín que acompañan las palabras adecuadas con que se reduce un espíritu débil, ya vencido. ¡Con qué cautelosa y calculada oportunidad, aquella gata sabía arquear el lomo bajo la caricia de un hombre dispuesto de antemano a todos los abandonos! ${ }^{21}$ devorado, lo ha "soldado" a su propio ser y por tanto ha vencido su "criollismo". Jacobo 
es un cholo más, generando el "descenso de un señorito en el abismo abierto por aquellos labios plebeyos"22. El sociólogo boliviano Salvador Romero (La Paz 1938-2012), en su libro Las Claudinas señala la diferencia entre la relación fugaz y la convivencia de un criollo y una chola:

El encholamiento trastocaba las jerarquías establecidas, subvertía las instituciones, produciendo la desaprobación y la exclusión para quienes se entregaban a su encanto. Si la posesión transitoria de la mujer en una sociedad machista confirma la hombría del varón y aún su status de caballero, la relación permanente desclasaba, arrimaba al amante al mundo cholo. ${ }^{23}$

Jacobo, en su concubinato con Claudina se "desclasa" y este "estado" no sólo es moral sino físico:

Por singular contraste, Jacobo, tan acicalado antes en el vestir, llevaba de ordinario el traje manchado, el cuello dudoso, la corbata raída [...] Su rostro fresco de muchacho lucía una máscara agobiadora de ceniza. ${ }^{24}$

Jacobo ha sido vencido, su amigo, el narrador omnipresente contempla la disolución de este señorito en la muchedumbre boliviana, su "hundimiento": "Y dándome la espalda, el infeliz se marchó. Lo seguí con la mirada y lo vi hundirse - para siempre- en un remolino de indias y de cholas." 25

Pese a la destrucción de Jacobo, su mimetización en el "remolino de indias y cholas", el narrador se mantiene intacto. La mirada criolla que tiene la autoridad del testigonarrador ha sobrevivido y puede construir esta moraleja de casta: la aristocracia que entra al juego de las Claudinas pierde su propio ser.

Si vinculamos estas narraciones literarias con el registro histórico y el análisis social, ¿por qué empieza a producirse este cambio en el imaginario criollo sobre la chola, de femme fatale a madre? ¿Es que los procesos de "encholamiento" se han intensificado en esta época?

27 Tengo la impresión de que el "poder" de la Claudina para envilecer a los criollos, que aparece en Costa du Rels y aún en Jaime Mendoza proviene del escenario literario que seleccionan: los centros mineros. Recordemos que las anteriores novelas son escenificadas en ciudades ${ }^{26}$. De tal manera, las Claudinas son más poderosas porque se desenvuelven en un ambiente cholo: Llallagua y Uyuni, el primero, centro minero, el segundo, estación de trenes y de comercio, ambos en vertiginoso crecimiento poblacional por el auge de la explotación del estaño. Estos espacios productivos, articulados al mercado mundial, son escenarios con características especiales, no migran familias criollas enteras, los señoritos entonces llegan a espacios habitados por mineros y comerciantes. En cuanto a la población obrera, también es necesario resaltar que la población indígena que habita el centro minero va perdiendo vínculos con las comunidades, es decir, existe un proceso de proletarización y también de mestizaje. Estamos, en este sentido, en un escenario privilegiado de "cholificación" o mestizaje de indígenas y criollos, que es revelador de la relación entre la identidad mestiza y la identidad minera que marcará la posterior Revolución Nacional de 1952.

La narración de estos espacios vinculados a la explotación de materias primas para el mercado internacional, por ejemplo, fue objeto de las reflexiones y desesperación del escritor peruano José María Arguedas, quien en su última novela, El zorro de arriba y el zorro de abajo (1971), relata la muerte del mundo andino en Chimbote, ciudad costeña dedicada a la pesca para la exportación. La disolución del sujeto andino, del indígena que entre los bares, prostíbulos, la miseria y un mundo grotesco pierde su vínculo con la 
comunidad y la cultura de origen, se convierte en la disolución del propio José María Arguedas, quien intercala los capítulos de la novela con el relato de su crisis y suicidio. En los centros mineros bolivianos, en cambio, se narra la disolución del sujeto criollo en el mundo cholo, popular. La mina se alegoriza con la "boca maldita" de la chola, que devora la voluntad de ser del criollo, tragándolo en sus entrañas.

La dinámica social y cultural en los centros mineros, a la que estos escritores respondían, permite suponer que la explotación de estaño durante este período generó intensos procesos de mestizaje en los centros mineros y la acumulación de riqueza en sectores mestizos/cholos, a través del comercio y el contrabando de mineral, como sucedía en el siglo XIX con la plata, lo que no se contradice con la existencia de una cadena comercial en donde la explotación y las masacres de los mineros y sus familias, creaban el capital del que vivió el superestado minero de Simón Patiño, Mauricio Hoschild y Avelino Aramayo y sus administradores políticos, "la rosca", durante la primera mitad del siglo XX. Si algunos grupos mestizos y cholos pudieron hacer fortuna en la minería y articularse a esta cadena capitalista que explotó a los mineros, los patrones culturales de la masa obrera no sucumbieron a la homogeneización proletaria que se vivía en Chimbote. La subjetividad chola se mantuvo y aún pudo imponerse a la criolla, aunque sólo sea en el interior del espacio minero, y que más adelante adquirió contornos políticos desencadenando la revolución nacional.

\section{La última Claudina}

La última chola de esta trilogía es La Chaskañawi ("la de los ojos de estrella") de Carlos Medinaceli. Esta es la historia de Adolfo Reyes, criollo natural de San Javier de Chirca pero que se va a estudiar derecho a Sucre. En unas vacaciones, Adolfo retorna a su pueblo para arreglar asuntos de herencia por la muerte de su padre, pero los amores con una chola lo hacen abandonar la vida letrada y urbana por la agricultura y el ambiente rural. 
Imagen 2

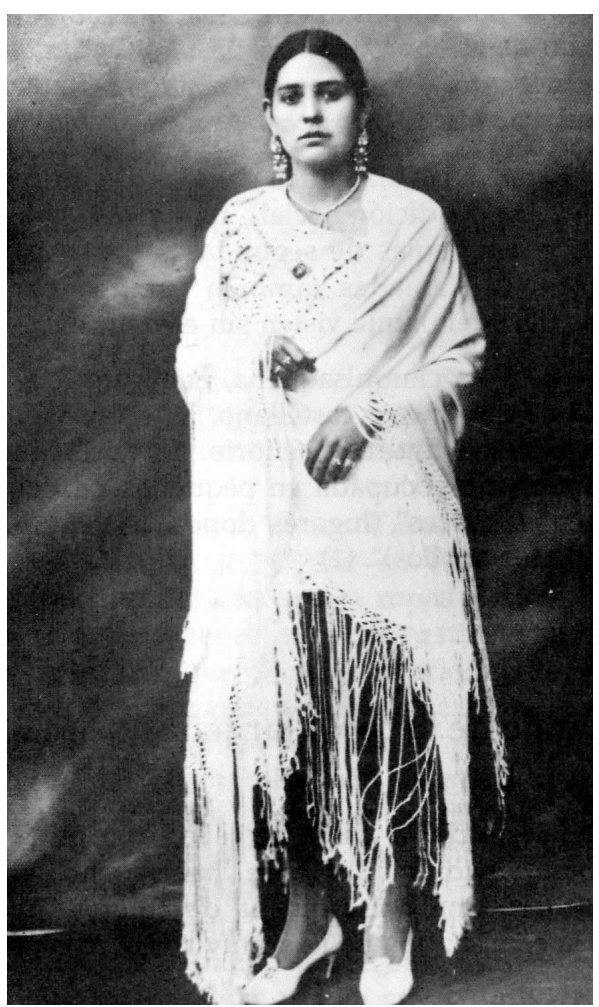

Doña Fidalia Valda Galarza de Ari, Sucre", Antonio Paredes Candia, La chola boliviana. La Paz, Isla 1992

31 Al inicio de esta obra, Medinaceli retoma la temática de Costa du Rels, pero va apartándose poco a poco de ella, convirtiéndose en tal vez el único escritor criollo del siglo XX que asume el "encholamiento" como posibilidad nacional.

Uno de las primeras escenas en San Javier de Chirca es el encuentro entre Adolfo y su primo Aniceto, quien hacía un tiempo vivía con una chola:

Mientras libaban, Adolfo pensó en Aniceto. ¡A lo que había llegado!... Rememoró su figura apenas hacía cuatro años, cuando lo dejó; entonces era un joven [....] distinguido. Se las daba de tenorio. Y ¿ahora? [....] En toda su persona se acentuaba ese hálito de fatalismo que flota como una maldición sobre las almas vencidas, los hombres resignados a la desventura, como pasa también con las casas abandonadas. 27

33 Esta apreciación sobre el "descenso" de su primo coincide plenamente con el final del cuento de Costa du Rels. Adolfo, al igual que el narrador de La Miski Simi, analiza la "maldición" del encholamiento en señoritos de "almas vencidas" por este fatal destino. Sin embargo, durante la obra se teje el conflicto interno de Adolfo, quien después de estar un tiempo en San Javier de Chirca, comienza a abandonarse a Claudina y convertirse en lo que criticó.

Durante su estadía, Adolfo tiene como amigo y confidente a Fernando Díaz, criollo que trabaja en un centro minero en Potosí, pero que está de vacaciones en el pueblo. Fernando tiene una historia de amor con una señorita de San Javier de Chirca, pero decide volver a "la civilización", al centro minero donde trabaja. Doce años después, Fernando vuelve y encuentra a su amigo Adolfo, quien aún vive con Claudina, tiene tres hijos y se dedica a la agricultura. En general, se lo ve joven, trabajador y próspero, en cambio 
Fernando está avejentado y arruinado en los negocios. En la última escena de la novela, Fernando comenta la desgracia de su amigo, pero otro criollo lo corrige señalando:

Adolfo necesitaba una mujer así, que lo maneje y domine y tenga la fuerza que ella tiene [....] Porque el Adolfo es como una guagua, sin voluntad, sin carácter, inútil para la vida. Él necesitaba una mujer como la Claudina, que lo envuelva, que lo waltte [envuelva en pañales como niño) porque él es de esos hombres que no pueden vivir de otro modo si no es abrigados bajo las polleras de la chola. ${ }^{28}$

¿Cuáles son los motivos de esta transformación, cómo se diferencia el "encholamiento" de Adolfo con el de los amantes de las Claudinas? Adolfo ha sido víctima de una chola como lo fueron los protagonistas de En las tierras del Potosí y La Miski Simi, pero Medinaceli convierte el fatalismo en necesidad vital: "él es de esos hombres que no pueden vivir de otro modo si no es abrigado bajo las polleras de la chola". Medinaceli realiza un giro de significación en el encholamiento deja de ser decadencia y hundimiento y se transforma en la única vía de salvación del mundo criollo en América:

La chola es matriz donde el indio ancestral refunde su milenario estatismo para cobrar el impulso energético de las razas en trance ascencional. Prueba de esto es la admirable capacidad de trabajo de la chola, su maravilloso sentido materno, su ímpetu de cañón disparado de la nacionalidad y de la raza hacia el porvenir. ${ }^{29}$

El sometimiento del hombre a la mujer, del criollo a la chola y de la cultura occidental a la "naturaleza" nativa ya no es el fin de la raza criolla sino su fuente de vida: "Adolfo era para ella el hombre deshumanizado de la civilización que se somete a la hembra todopoderosa, eterna aliada de la vida y de la naturaleza." ${ }^{30}$

En su época, la propuesta de Carlos Medinaceli es más radical que la del poeta y ensayista Franz Tamayo (La Paz 1879-1956) porque este último autor aún necesita diferenciar al mestizo letrado del cholo para convertirlo en su ideal nacional. De igual manera, Nataniel Aguirre (Cochabamba 1843 - Montevideo 1888) en Juan de la Rosa (1885) convierte al niño mestizo en un ciudadano letrado, digno de continuar la misión heroica de los independentistas. En cambio Medinaceli realiza una ruptura con la cultura occidental letrada que sus predecesores (Tamayo y Aguirre) mantenían, por eso la chola, alejada de la "ciudad letrada" y vinculada a la tierra y a la naturaleza es sublimada.

Esta imagen también difiere de otra novela fundacional que se publica en la misma época que la obra de Medinaceli, La niña de sus ojos (1948) de Antonio Díaz Villamil. En esta novela, la protagonista es una mestiza (hija de una chola) que debe aculturarse - léase dejar de ser chola e integrarse a la cultura occidental- para encarnar la nación. Para el proyecto de Medinaceli, en cambio, la chola es válida como símbolo nacional precisamente porque se aparta de un occidente en decadencia. Medinaceli construye el conflicto interior de su protagonista, Adolfo, como la agonía de occidente, su inadaptabilidad en las tierras andinas:

Soy, pues, y no hay remedio para ello, un "fin de siglo", un alma crepuscular de Occidente extraviada en lo agresivo de estas breñas de América. Por eso hay un cósmico divorcio entre mi alma - que es de otra parte- y el paisaje que me rodea, que yo no lo puedo sentir, y, menos vivir de acuerdo con él. Por eso hay en mí un desequilibrio, una insatisfacción, un estado de no encontrarse nunca [....] De ahí que, de raíz, yo he nacido para no vivir mi vida "en su plenitud", sino fragmentariamente. ${ }^{31}$

40 Este "estado de no encontrarse nunca" de Adolfo, su vacío existencial se refiere a la desubicación - temporal y espacial - de la identidad criolla, un "divorcio cósmico" entre la subjetividad criollo-occidental que asumió la élite liberal y el medio físico y cultural 
nacional que debía ser reparado. A partir de esta crítica a occidente, su relación con Claudina deja de ser de abandono, hundimiento y perdición, para convertirse en "salvación". De tal manera, Carlos Medinaceli transforma la dicotomía civilización/ barbarie que había dominado el pensamiento latinoamericano del siglo XIX e inicios del XX y que era el marco reflexivo sobre las Claudinas de Costa du Rels y Mendoza, por la dicotomía civilización/naturaleza (o social/natural ${ }^{32}$ ). El mestizaje así planteado, entonces, no apunta a la integración o aculturación de lo indígena, sino al retorno a la tierra, al origen: Adolfo y Claudina "se encontraban solos, lejos del mundo, frente a la naturaleza; eran el hombre y la mujer, casi vueltos a la edad primitiva, edénica" ${ }^{33}$.

La Chaskañawi es una narrativa de génesis nacional y su eje central es la chola-madre, figura que no está presente con las anteriores Claudinas, así En las tierras de Potosí, le comentan a Jacobo respecto a las madres mineras:

- ¡Y si usted viese otras cosas que hacen estas malditas! A criaturas de pocos meses les dan carne, frutas, chicha, ají. Les ponen unas envolturas con las fajas tan apretadas, que las guaguas resultan más tiesas que un palo. Las tienen al frío, a la lluvia, al sol, a la nieve, al viento. Las pegan con crueldad. En sus borracheras se acuestan con frecuencia sobre ellas y las ahogan ${ }^{34}$.

Aquí la chola es una cortesana y por tanto no tiene un rol reproductivo o engendra hijos bastardos, o si lo tiene, como se muestra en la cita, aún pertenece al polo de la "barbarie", una "maldita" que llega a matar a su propio hijo en sus borracheras. Con Medinaceli, en cambio, se presenta la imagen de la chola madre que está en boga en el Perú con el neoindigenismo de Uriel García y otros letrados. En Bolivia, al igual que en el Perú, sin embargo, la construcción de la imagen de la chola como madre de la nación responde a un proceso de selección de las otras "candidatas", es decir, nombrar a la chola-madre implica deslegitimar el rol materno simbólico de criollas e indígenas, sobre todo estas últimas. Precisamente la siguiente es una cita de García en su libro El nuevo hombre, transcrita por Carlos Medinaceli:

Mientras la india tradicional -añade- madre de la chola, conserva su pureza primitiva, su alma recia y nómada, en constante fuga del tiempo, la chola es la fuerza orgánica rejuvenecida que avanza desenvuelta y sin miedo hacia la ciudad y hacia el presente, nutriendo pechos opimos y maternales, la energía varonil de la raza, como madre o como nodriza, con su tufo de chicha y su huaiño en la garganta, como fragancias sierraniegas. La mujer india es la tradición madura y casi envejecida, por incambiable o poco plástica, de un pasado milenario. La chola es el rejuvenecimiento de esta mujer que engendró la indianidad o espíritu acrecentado de aptitudes germinales. ${ }^{35}$

En esta comparación, la indígena no puede representar el rol de madre de la nación porque está anclada en el pasado, "envejecida", "en constante fuga del tiempo"; la chola, en cambio, "avanza desenvuelta y sin miedo hacia la ciudad y hacia el presente", es hija de este tiempo y por tanto está adaptada para sobrevivir y nutrir a la nación con sus "pechos opimos y maternales". Así como Medinaceli se apoya en el pensamiento de Uriel García, él mismo realiza una comparación entre la potencialidad materna de criollas, indígenas y cholas:

La chola que constituye no solamente el elemento pintoresco y característico del país sino también el más rico de vitalidad orgánica, creadora, de pasionalidad efusiva y, por eso mismo de enjundia para el teatro y la novela. La chola es el elemento básico de la nacionalidad. Ella representa el elemento más sano, laborioso y próspero de la patria. La chola vale psicológicamente hablando más que la india. Esta es una anquilosada en el pasado, sin plasticidad para el presente $y$, en cuanto a la "señorita" es un tipo que corresponde a una moral "a la antigua española" pero 
carece también de porvenir porque vive con una moral escolástica, en un ambiente dinámico y creador. Tendrá que transformarse si quiere sobrevivir. ${ }^{36}$

Para Medinaceli, las mujeres indígenas y criollas viven fuera de este tiempo, anquilosadas en códigos morales y culturales pasados y por tanto incapaces de nutrir a la nación. La chola, en cambio, es "el elemento básico de la nacionalidad" porque es el fruto germinal de esta tierra, ya no es la indígena correspondiente al pasado prehispánico ni la criolla, heredera de la colonización española; la chola es el presente y el porvenir por ser la mezcla de ambas, un producto nuevo y flexible a los cambios de la época ${ }^{37}$.

El mestizaje de Medinaceli se proyecta como simbiosis, pero donde aparece privilegiada la naturaleza frente a la civilización. Así, la visión futura de la nación, representada en el hijo de ambos debe ser:

El hijo de esta mujer -se dijo Adolfo-, Dios quiera que sea más hijo del creador sentido de la Naturaleza de ella, antes que del atormentado espíritu mío: entonces será el fruto genuino y sano de estas fuertes sierras andinas, lejos de toda la crápula intelectual de Europa. ${ }^{38}$

¿Cómo evaluar La Chaskañawi y cuáles son las consecuencias de este discurso en el imaginario de la época? Carlos Medinaceli es el único intelectual del siglo XX que propone el "encholamiento" como proyecto nacional. Su Claudina no requiere educarse en la cultura occidental, dejar de ser chola y convertirse en mestiza, como sucede con la propuesta de La niña de sus ojos. Claudina no necesita pedagogía o aculturación porque Medinaceli ha identificado la agonía de un occidente que ya no tiene nada que dar, que está en decadencia. En cambio, occidente, lo occidental de Bolivia, lo criollo sí puede revitalizarse con este retorno a la tierra, a lo nativo, a las polleras de la chola.

Sin embargo, y pese a la "radicalidad" de Medinaceli en su tiempo, su discurso tiene límites. La propuesta de Carlos Medinaceli se queda en la estetización de la chola que no contempla ninguna agencia real, ni económica ni política en la sociedad de su época. Se sublima a la chola como madre, pero las consecuencias de este discurso son encasillarla en un ámbito privado familiar y eliminarla de la escena pública (política y económica).

B De tal manera, Carlos Medinaceli, aunque se diferencia de los paceños en su sublimación de la chola (chichera), comparte con ellos la barbarización del cholo y su exclusión política. La presencia del tata Pérez, cura cholo que agita a la masa de artesanos de San Javier de Chirca a favor del Partido Republicano rompe la armonía estética que el autor emplea con la Claudina y retoma el discurso crítico a la democratización política chola de los autores Armando Chirveches en La candidatura de Rojas (1908) y Enrique Finot en El cholo Portales (1926).

Las descripciones de la vitalidad del "elemento básico de la nacionalidad", la chola, se contraponen a los adjetivos empleados para describir la presencia de los cholos en las elecciones presidenciales en San Javier de Chirca: "La horda republicana"39, "pandilla de forajidos", "hediondos saavedristas que andaban envalentonando a la cholada", "La cholada había dominado el pueblo", "zapateros, remendones, herreros, sastres y pollereros, greñudos, rotosos y malolientes". ¿Es posible considerar esta apreciación opuesta del cholo y de la chola como una contradicción del autor? Creo que no. El pensamiento de Medinaceli, descrito hasta ahora, como de los autores de este "neoindigenismo" o discurso de mestizaje no se diferencian de los anteriores en su opinión sobre la participación política de los cholos. El límite en el discurso sobre las Claudinas es su estetización, la chola y la energía vital que representa su cultura es válida 
tan solo a condición de símbolo nacional, es decir, reducida a ícono sin agencia, en tanto los(as) cholos(as) de carne y hueso quedan excluidos de la arena pública.

Quisiera terminar este ensayo hablando brevemente de una "cuarta" Claudina que aparece en 1954, quizá como reacción a la violencia revolucionaria (tomas de tierras, disputas sindicales) que viven los intelectuales, aún aquellos que apostaron por las ideas nacionalistas desde la Guerra del Chaco (1932-1935), pero que también reinscribe el discurso anti-cholo del período liberal. Se trata de La cruel Martina ${ }^{40}$, cuento del escritor cochabambino Augusto Guzmán, cuya protagonista, Martina, encarna a las Claudinas anteriormente analizadas, pero lleva la voracidad chola hasta sus últimas consecuencias.

Martina nace en la "calle del Diablo", no se especifica la ciudad, donde su madre tenía una chichería. Martina nace con la marca de rechazo materno porque su madre intenta abortarla varias veces, sin lograrlo y su padre, el Tunas Molle, es un cholo músico al que nunca conoce. Las condiciones de su nacimiento y el abandono de sus progenitores (se cría con una tía), se reflejan en su carácter hostil:

En su alma árida y desnuda de amores no había germinado la planta de la ternura. Ni siquiera le simpatizaba el otro sexo. Por el contrario, sentía en la sangre, en las entrañas vírgenes, un odio mortal a los hombres que parecía venirle, instintivo e incontrolable, con remoto impulso hereditario, del ancestro. ¿No habría sido así su madre? ${ }^{41}$

El rechazo a los hombres y al romance la hace famosa en la zona y le ganan el apodo de "la cruel Martina". Sin embargo, un nuevo corregidor llega al poblado y asedia a Martina con sus insinuaciones, hasta que sin obtener ninguna atención suya, la viola y la deja embarazada:

Desde el impacto de la revelación, [Martina] lloraba sin consuelo porque iba a tener un hijo como otras lloran por haberlo perdido. Sin embargo nada hizo por secundar los frecuentes consejos acerca de esfuerzos musculares, de tocamientos y de yerbas a tomar que podían procurarle un aborto. Un oscuro terror orgánico, especie de miedo visceral, la poseía paralizándola en los proyectos. Pero al correr los días [...] brotaba un río violento de despecho y de odio. ${ }^{42}$

53 Como se observa, Martina es tan deseada como las Claudinas pero ya no es caprichosa en sus juegos con los hombres, simplemente los aborrece. Su rol materno también ha sido eclipsado, su embarazo le provoca tanto llanto como el de una "madre normal" al perder un hijo. Es más, la energía vital que le daba una maternidad simbólica de la nación, aquí se ha convertido en "un oscuro terror orgánico, especie de miedo visceral". Martina no es una madre ideal, ni siquiera una femme fatale, es un producto grotesco del odio hacia los hombres criollos.

Llega el momento del nacimiento de su hijo y la trama se prepara para la transformación de una mujer desalmada en madre ejemplar, sin embargo, el final del cuento invierte esta expectativa. Martina, con su hijo en brazos, muestra un desliz de sentimientos al invitar al corregidor a cenar en su casa, la tía cree que ha llegado la reconciliación. Martina sirve la cena que deleita a todos, pero cuando le pregunta por el bebé, ella responde: “¿Cómo puedo yo traerles el niño, si ustedes mismos acaban de comérselo?" 43

La hembra pródiga y fecunda, la madre de la nación de Carlos Medinaceli se ha convertido en una antropófaga que come y da de comer a su propio hijo. El proyecto de estetización de la chola se ha desgastado en la próxima generación y se retorna a su barbarización liberal o aún peor. Martina ni siquiera representa a Domitila, de El cholo Portales, quien a pesar de ser promiscua, era buena madre, anhelaba que su hijo se hiciera abogado. Martina también es peor que su propia madre que quiso abortarla, ella tiene un hijo para 
devolvérselo a su violador a través de la comida, su odio hacia los hombres se realiza en este acto de digestión de su propio hijo. La revolución mestiza no tiene porvenir, su propia madre - que no pudo abortarla- la sirve en la mesa "de reconciliación" interracial para deglutir este proyecto "mal nacido".

¿Moraleja? El deseo y la progenie con una chola no sólo conduce a la degradación criolla sino que acaba en el peor acto humano: antropofagia y filicidio. Este es el resultado de los errores de sublimación de la chola, ¿la Revolución Nacional de 1952 vuelve a su origen elitista?

\section{NOTAS}

1. Este artículo proviene de la investigación realizada y publicada en Ximena Soruco, La ciudad de los cholos. Mestizaje y colonialidad en Bolivia, siglos XIX y XX, La Paz, IFEA-PIEB, 2012.

2. La chola es una mujer mestiza urbana que utiliza ropa española del siglo XVIII, trenzas y un sombrero borsalino y por tanto se diferencia de la mujer mestiza y criolla que utiliza ropa occidental de moda. Ver las imágenes de este artículo.

3. Ximena Soruco, Literatura y sociedad boliviana. Clases y desclasamientos en Carlos Medinaceli. La Paz, Plural, 2016.

4. "Medinaceli era Profesor Fiscal cuando empezó en 1923 su novela [...] allá por 1936 fue concluida en La Paz. [...], Pero la terminación del libro no dio fin a la tarea de pulirlo, hasta que en 1939 el autor quedó medianamente satisfecho" (Raúl Botelho Gosálvez, en Mariano Baptista Gumucio, Atrevámonos a ser bolivianos, Vida y epistolario de Carlos Medinaceli, La Paz, Los Amigos del Libro, 1984). Finalmente se publica en 1947.

5. Ibid., p. 159-189; Salvador Romero, Las Claudinas, Libros y sensibilidades a principios de siglo en Bolivia, La Paz, Caraspas, 1998.

6. Brooke Larson, Colonialismo y transformación agraria en Bolivia. Cochabamba, 1550-1900, La Paz, BBB, 2017 [1988], Gustavo Rodríguez y Humberto Solares, Sociedad oligárquica, chicha y cultura popular, Cochabamba, Serrano, 1990 y Huáscar Rodríguez, "Diferentes pero unidos y en pie de guerra. Los sentidos del liberalismo en Cochabamba a fines del siglo XIX" en Ximena Soruco et. al. Vértigo liberal en Bolivia. La Paz, IIL, en prensa.

7. Jaime Mendoza, En las tierras del Potosí, La Paz, Puerta del Sol, 1976 [1911], p. 208.

8. Ibid., p. 117.

9. Ibid., p. 215.

10. "Jaime Mendoza, destacado intelectual boliviano y autor de numerosas obras de literatura e historia, era jefe de servicios médicos de la empresa 'Patiño Mines \& Enterprises, Consolidated Incorporated' en el asiento minero de Uncía, al norte del departamento de Potosí, cuando nació su único hijo varón, Gunnar, en el año del estallido de la primera guerra mundial. Su padre, don José María Mendoza, fue abogado de la Universidad de San Francisco Xavier. Era, según la tradición familiar, una familia pudiente que con el tiempo perdió gran parte de su fortuna. La madre de Gunnar, Matilde Loza, de origen más humilde que don Jaime, era natural de Llallagua [ ....] fue un hogar muy unido a pesar de las diferencias socio-económicas entre don Jaime y doña Matilde y a pesar de que la unión matrimonial solo fue formalizada poco antes de la muerte de don Jaime, en 1939, cuando su hijo Gunnar tenía veinticuatro años” (William Lofstrom, “Gunnar 
Mendoza: ensayo biográfico" en Anuario de Estudios Bolivianos, Archivísticos y bibliográficos No. 20, Sucre, AHNB, 2014, p. 18-19, mi énfasis).

11. Adolfo Costa du Rels, "La Miskki Simi”, en Armando Soriano, Antología del cuento boliviano, Tomo II, La Paz, Los Amigos del Libro, 1998, p. 58.

12. Ibid., p. 62.

13. Taberna donde se sirve la chicha (maíz fermentado), platos tradicionales, hay música y baile. Las chicherías eran de propiedad y administración de mujeres de pollera a las que frecuentaban hombres de diferentes clases sociales.

14. Ibid., p. 60.

15. Jaime Mendoza, op. cit., p. 187.

16. Adolfo Costa du Rels, op. cit., p. 63.

17. Ibid., p. 61.

18. Ibid., p. 63.

19. Jaime Mendoza, op. cit., p. 118 , mi énfasis.

20. Adolfo Costa du Rels, op. cit., p. 60, mi énfasis.

21. Ibid., p. 63-64.

22. Ibid., p. 65.

23. Salvador Romero Pittari. Las Claudinas. Libros y sensibilidades a principios del siglo XX en Bolivia. La Paz, Caraspas, 1998, p. 62.

24. Adolfo Costa du Rels, op. cit., p. 64.

25. Ibid., p. 70.

26. La Paz en El cholo Portales (1926), Sucre en La casa solariega y capitales de provincia de La Paz en las demás novelas de Armando Chirveches.

27. Carlos Medinaceli, La Chaskañawi. Novela de costumbres bolivianas. La Paz, Juventud, 1967, [1947], p. 16.

28. Ibid., p. 222.

29. En Mariano Baptista Gumucio, Atrevámonos a ser bolivianos. Vida y epistolario de Carlos Medinaceli. La Paz, Los Amigos del Libro, 1984, p. 162.

30. Carlos Medinaceli, La Chaskañawi, op. cit., p. 180.

31. Ibid., p. 213.

32. Josefa Salmón, El espejo indígena. El discurso indigenista en Bolivia 1900-1956. La Paz, Plural, 1997, p. 103-108.

33. Carlos Medinaceli, La Chaskañawi, op. cit., p. 179.

34. Jaime Mendoza, op. cit., p. 82.

35. Carlos Medinaceli, La inactualidad de Alcides Arguedas y otros estudios biográficos. La Paz, Los Amigos del Libro, 1972, p. 18-19.

36. En Bautista Gumucio, op. cit., p. 164, mi énfasis.

37. Y la Claudina encarna esta mezcla, ella aunque es hija ilegítima de un criollo respetado y fue educada "como una señorita, infiltrándole modales y comportamiento de persona decente, como que lo era por su padre" (Carlos Medinaceli, La Chaskañawi, op. cit., p. 170), acaba viviendo con su madre chola en la chichería. Sin embargo, la observación de Adolfo sobre Claudina cuando va a visitar a la hermana de su padre, donde heredará su hacienda es inquietante: "en el fondo, ella se sentía más hija de doña Clara, que de su propia madre. Se encontraba mejor ambientada en Mollepampa mandando sobre peones y mittanis sumisos, como 'una señora de rango', que en su vergonzante tenducho de Chirca, vendiendo singani detrás del mostrador”. Ibid., p. 172.

38. Ibid., p. 214-215.

39. Ibid., p. 181 y las siguientes en el orden de aparición: p. 182, p. 32, p. 166 y p. 162.

40. El cineasta boliviano Juan Miranda ha realizado una producción de video que lleva el título de este cuento y que en 1989 ganó el premio "Cóndor de Plata" en la versión 16 del festival de cine 
boliviano "Llama de Plata”. De igual manera, en 1976, José Cuellar Urízar realizó un largometraje sobre la novela de Medinaceli, La Chaskañawi.

41. Augusto Guzmán, La cruel Martina. Cochabamba, Los Amigos del Libro, 1997 [1954], p. 19-20.

42. Ibid., p. 27.

43. Ibid., p. 39.

\section{RESÚMENES}

Este ensayo muestra la transformación en la representación de la chola en la literatura boliviana de la primera mitad del siglo XX y los procesos sociales que subyacen a ella. Su objetivo es matizar la interpretación de la historia boliviana como una lucha inmemorial entre estamentos criollos, mestizos, cholos e indígenas; lectura que imagina sujetos graníticos y a-históricos, y no procesos de movilidad entre estratos sociales que renuevan estas representaciones.

Cet essai aborde la transformation de la représentation de la "chola » dans la littérature bolivienne de la première moitié $\mathrm{du} \mathrm{xx}^{\mathrm{e}}$ siècle et les processus sociaux qui en découlent. L'objectif est de réviser l'interprétation de l'histoire bolivienne réduite à une lecture de la lutte immémoriale entre les couches sociales (criollos, cholos et indigènes) comme sujets immuables et a- historiques au détriment du processus de mobilité entre les couches sociales que renouvellent ces représentations.

\section{ÍNDICE}

Mots-clés: chola, représentations, littérature, nation, Bolivie

Keywords: chola, representaciones, literatura, nación, Bolivia

\section{AUTOR}

\section{XIMENA SORUCO SOLOGUREN}

Universidad Mayor de San Andrés (UMSA), La Paz - Bolivia 